
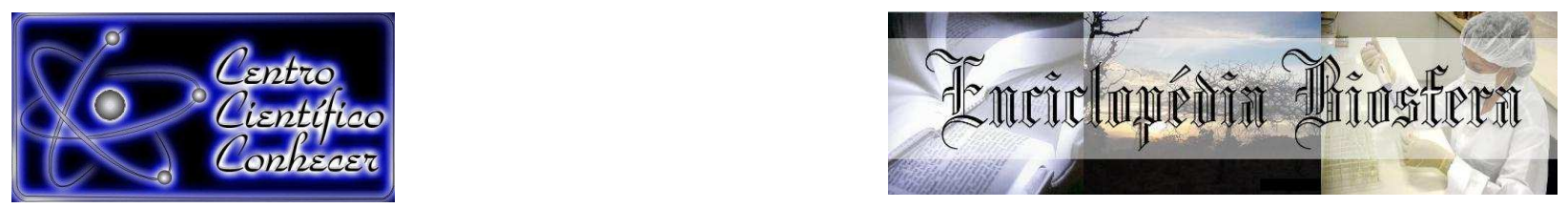

\title{
ESTUDO DO PROCESSO DE SECAGEM EM LEITO DE ESPUMA DE SORO DE LEITE ADICIONADO DE CLARA DE OVO
}

Pamela Lemos Cruz¹, Sérgio Henriques Saraiva², Luciano José Quintão Teixeira²

1 Mestranda no programa de Ciência e Tecnologia de Alimentos da Universidade

Federal do Espírito Santo (pamelaceng@gmail.com) Alegre-Brasil.

2 Professor Associado do Departamento de Engenharia de Alimentos da

Universidade Federal do Espírito Santo.

\section{Recebido em: 02/10/2017 - Aprovado em: 21/11/2017 - Publicado em: 05/12/2017}

DOI: 10.18677/EnciBio_2017B31

\begin{abstract}
RESUMO
Indústrias em todo o mundo processam anualmente milhões de toneladas de produtos proteicos, gerando grande quantidade de resíduos ricos em proteínas que têm despertado crescente interesse em seu aproveitamento. Na secagem em leito de espuma, o alimento é convertido em uma espuma estável por meio da adição de agentes espumantes. O objetivo desse trabalho foi estudar a secagem em leito de espuma de soro de leite adicionado de clara de ovo, sem a necessidade de adição de agente espumante, uma vez que tanto as proteínas do soro quanto as da clara de ovo possuem propriedade espumante. Foram testadas seis proporções de clara a ser adicionada ao soro de leite (14,94, 27,36, 35,93, 52 e 76,4\%) e a estabilidade da espuma formada foi estudada. Foi escolhida a proporção de $52 \%$ por apresentar condições ótimas na formação da espuma. Em seguida, avaliou-se o efeito da temperatura $\left(50,55,60,65\right.$ e $\left.70^{\circ} \mathrm{C}\right)$ sobre as cinéticas de secagem comparando-se os modelos de Page, Henderson e Pabis e Exponencial. O modelo de Page foi o que melhor se ajustou aos dados experimentais, com um coeficiente de determinação $\left(R^{2}\right)$ superior a 0,99 em todos os casos. O produto obtido no processo de secagem foi submetido à análise de umidade, apresentando valores de $2 \%$ na maior temperatura de secagem $\left(70^{\circ} \mathrm{C}\right)$ e $8,5 \%$ na menor temperatura de secagem $\left(50^{\circ} \mathrm{C}\right)$. O pó resultante foi reconstituído e apresentou boa capacidade de formação de espuma, formando espumas com alta densidade e baixa estabilidade nas temperaturas acima de $60^{\circ} \mathrm{C}$.
\end{abstract}

PALAVRAS-CHAVE: coprodutos; desidratação; modelo de Page; regressão nãolinear.

\section{STUDY OF THE PROCESS OF FOAM-MAT DRYING OF WHEY WITH ADDED WHITE EGG}

\begin{abstract}
Industries around the world process millions of tonnes of protein products annually, generating large amounts of protein-rich waste that has generated increasing interest
\end{abstract}


in its use. In foam mat drying, food is converted into a stable foam by addition of foaming agents. The objective of this work was to study the foam mat drying of cheese whey added with egg white, without addition of foaming agent, since both whey and egg white proteins have foamy properties. Currently, the reuse of byproducts and industrial co-products stands out as one of the most arduous tasks of the food industry. Foam bed drying comes as an alternative to preserving products, improving their stability and adding value to the final product. Initially, six ratios of clear to be added to the whey $(14.9415,27.3627,35.9336,52$ and $76.4 \%)$ were tested and the stability of the formed foam was studied. The proportion of $52 \%$ was chosen because it presented close reductions in foam density and stability when compared to the greater proportion of optimal foam formation conditions. After drying, the effect of temperature $\left(50,55,60,65\right.$ and $\left.70^{\circ} \mathrm{C}\right)$ and its drying kinetics were adjusted by comparing the Page, Henderson and Pabis and Exponential models by means of a Non-linear regression, establishing the drying curve of the process. The Page model was the best fit for empirical and experimental data, with a coefficient of determination $\left(\mathrm{R}^{2}\right)$ of more than 0.99 in all cases. The product obtained in the drying process was submitted to moisture analysis, presenting values of $2 \%$ at the highest drying temperature $\left(70^{\circ} \mathrm{C}\right)$ and $8.5 \%$ at the lower drying temperature $\left(50^{\circ} \mathrm{C}\right)$. Finally, the resulting powder was reconstituted and showed good foamability, forming foams with high density and low stability at temperatures above $60^{\circ} \mathrm{C}$.

KEYWORDS: dehydration; co-products; nonlinear regression; Page model.

\section{INTRODUÇÃO}

Os subprodutos e coprodutos industriais são considerados comuns em indústrias de alimentos, como qualquer outra, e busca-se uma alternativa para que estes não sejam eliminados, muitas vezes de forma a poluir o meio ambiente. Dentre estes coprodutos estão o soro de leite e a clara de ovo. O primeiro está ligado diretamente às indústrias de laticínios, principalmente na produção de queijo, e o segundo está ligado à produção de diversos produtos como sorvetes e maioneses, que utilizam a gema, e a clara acaba sendo excedente nesses processos (SERAFINI et al., 2017).

Opções para o aproveitamento desses coprodutos tão ricos nutricionalmente e com propriedades funcionais únicas foram desenvolvidas, desde nutracêuticos, como os suplementos alimentares, bem como bebidas lácteas a base de soro de leite (CUNNINGHAM; LINEWEAVER, 1965; MADUREIRA et al., 2010; VARGAS et al., 2014; PERREAULT et al., 2017).

Porém muitos desses produtos alimentícios são perecíveis. Neste caso, a utilização de soro de leite e clara de ovo requer altos investimentos com transporte em caminhões climatizados e armazenados em frigoríficos de alta potência com o objetivo de evitar contaminação bacteriana. Configura-se então, um custo elevado num processo que visaria a reutilização desses coprodutos (MADUREIRA et al., 2010; SERAFINI et al., 2017).

A necessidade de conservar alimentos levou o homem a desenvolver diversos processos, dentre estes, a desidratação de alimentos. Esta técnica é um dos processos mais antigos que existem, e consiste em retirar a água livre dos alimentos e melhorar a estabilidade microbiológica. Este processo passou por muitas mudanças ao longo do tempo com estudos e ajustes para preservar ao máximo a 
qualidade dos alimentos e, portanto, aprimorar o aspecto final. Adicionalmente, agrega valor aos produtos além de otimizar o processo, melhorando o tempo e a funcionalidade do mesmo (FELLOWS, 2006; MUTHUKUMARAN et al., 2008; MELO et al., 2013; FRANCO et al., 2015).

Nesse cenário surgiu o processo de secagem em leito de espuma, que consiste na formação de uma espuma estável do alimento a ser desidratado, por meio de agitação e, quando necessário, adição de emulsificantes. Esta espuma é espalhada em bandejas e submetida à passagem de ar quente para a desidratação. O processo é rápido e não necessita de grande exposição do alimento ao calor, gerando produtos de boa qualidade, tanto nutricional quanto sensorial (FELLOWS, 2006; MUTHUKUMARAN et al., 2008; MELO et al., 2013; FRANCO et al., 2015).

A secagem de produtos agrícolas pode ser descrita por modelos matemáticos que apresentam como objetivo estimar o tempo necessário para redução do teor de água do produto, sob diferentes condições de secagem (FELLOWS, 2006; MUTHUKUMARAN et al., 2008; MELO et al., 2013; FRANCO et al., 2015). Na prática, estes modelos auxiliam nas tomadas de decisão e contribuem na melhoria da eficiência do processo (MELO et al., 2013).

Dessa forma, faz-se necessário o estudo do processo de secagem em leito de espuma de produtos, neste caso o soro de leite e a clara de ovo, que adicionada em proporções ideais, torna o soro de leite passível para este tipo de processo. Isso pode ser explicado pela necessidade de uma espuma de estabilidade considerável para tal processo, e tanto a clara quanto o soro de leite, apresentam propriedades funcionais desejáveis nesse quesito (CUNNINGHAM; LINEWEAVER, 1965; MADUREIRA et al., 2010; MELO et al., 2013; VARGAS et al., 2014; PERREAULT et al., 2017).

O objetivo deste trabalho foi determinar a cinética de desidratação da espuma de soro com clara de ovo em diferentes temperaturas de secagem e propor um modelo matemático que descreva o efeito da temperatura de secagem sobre a cinética de secagem da espuma de soro com clara de ovo.

\section{MATERIAL E MÉTODOS}

O experimento foi realizado no Laboratório de Operações Unitárias, no Centro de Ciências Agrárias da Universidade Federal do Espírito Santo, localizado no município de Alegre-ES.

Foram obtidos ovos inteiros, provenientes do comércio local em Alegre-ES. Observou-se a integridade das cascas e a qualidade dos ovos previamente. As claras dos ovos foram separadas das gemas manualmente, com auxílio de uma colher e separadas em béqueres de vidro. O soro de leite utilizado foi cedido pela Universidade Federal de Viçosa.

Para determinar a quantidade de clara a ser adicionada ao soro, foi testada a adição inicial de 0 claras, para obtenção do referencial e em seguida foram testadas a adição de clara de um ovo, dois ovos, três ovos, quatro ovos e cinco ovos. Em cada teste, fixou-se a quantidade de $10 \mathrm{~g}$ de soro desidratado e após a adição da clara, completou-se o volume com água destilada até o total de $250 \mathrm{~g}$. Na Tabela 1, encontram-se os valores em porcentagem de clara das proporções utilizadas. 
TABELA 1- Porcentagem das proporções para as misturas testadas.

\begin{tabular}{cccc}
\hline $\begin{array}{c}\text { Número de Ovos em } \\
\text { que foram retiradas as } \\
\text { claras }\end{array}$ & $\begin{array}{c}\text { Peso de clara } \\
\text { total }(\mathbf{g})\end{array}$ & $\begin{array}{c}\text { Peso total da } \\
\text { mistura }(\mathbf{g})\end{array}$ & $\begin{array}{c}\text { Porcentagem } \\
\text { de clara (\%) }\end{array}$ \\
\hline $\mathbf{0}$ & 0 & 250 & 0 \\
$\mathbf{1}$ & 37,35 & 250 & 14,94 \\
$\mathbf{2}$ & 68,39 & 250 & 27,36 \\
$\mathbf{3}$ & 89,83 & 250 & 35,93 \\
$\mathbf{4}$ & 130 & 250 & 52 \\
$\mathbf{5}$ & 191 & 250 & 76,4 \\
\hline
\end{tabular}

Cada mistura foi agitada em uma batedeira planetária da marca ARNO por 20 minutos para a formação da espuma. Os cinco primeiros minutos foram mantidos na menor velocidade da batedeira, e os 15 minutos seguintes foram batidos com velocidade máxima.

Assim que a agitação na batedeira foi interrompida, o volume de espuma foi adicionado a uma proveta de dois litros e pesado, para obtenção da densidade através da razão entre o peso e o volume. Em seguida, mediu-se a quantidade de líquido drenado no fundo da proveta após 30 minutos de repouso, calculando-se o percentual de volume de líquido drenado em relação ao volume total da espuma. Uma espuma ideal deve ter uma baixa densidade, indicando incorporação de ar, e baixo valor de percentual de líquido drenado, indicando boa estabilidade da espuma.

Escolhida a melhor proporção para se obter espuma estável, foram preparadas as espumas para os experimentos de secagem. As amostras foram espalhadas em bandejas e seguiram para um secador com circulação de ar forçado, com temperaturas controladas de $50,55,60,65$ e $70^{\circ} \mathrm{C}$. Foi realizado o registro de massa das amostras de 15 em 15 minutos durante a primeira hora, 30 em 30 minutos durante a segunda hora e terceira hora, e de uma em uma hora até que a massa permaneceu constante. Terminada a secagem, o pó obtido foi armazenado em embalagens plásticas herméticas a temperatura ambiente.

A partir dos experimentos de secagem foram ajustados os modelos de Page, Eq. 1, Henderson e Pabis, Eq. 2, e o exponencial, Eq.3, para cada temperatura:

$$
\begin{aligned}
& R U=\frac{X_{t}-X_{\theta}}{X_{t}-X_{o}}=e^{-k t^{n}} \\
& R U=\frac{X_{t}-X_{\theta}}{X_{t}-X_{o}}=C e^{-k t} \\
& R U=\frac{X_{t}-X_{e}}{X_{t}-X_{n}}=e^{-k t}
\end{aligned}
$$

Em que $k, n$ e $C$ são parâmetros dos modelos, $R U$ é a razão de umidade, $X_{\mathrm{t}}$ é o teor de água em base seca em qualquer instante de tempo, $X_{e}$ é o teor de água na 
condição de equilíbrio, $X_{0}$ é o teor de água inicial e $t$ é o tempo de secagem em minutos.

Os modelos de curva de secagem foram ajustados por meio de análise de regressão não linear, usando a técnica de minimização da soma de quadrados dos desvios. Os modelos foram comparados com base no coeficiente de determinação $\left(R^{2}\right)$ e no valor do erro padrão da regressão (S), calculado a partir da equação seguinte:

$$
S=\frac{\sum_{i=1}^{n}\left(R U_{e x p i A}-R U_{p r e v i}\right)^{2}}{N-p}
$$

Em que $R U_{e x p, i}$ e $R U_{p r e v, i}$ são, respectivamente, os valores experimentais e previstos da razão de umidade para a i-ésima observação, $N$ é o número de observações e $p$, o número de parâmetros no modelo.

$\mathrm{O}$ efeito da temperatura do ar de secagem sobre os parâmetros do modelo foi avaliado, segundo o modelo que melhor descreveu a cinética de secagem. A partir do modelo escolhido, foi construído um gráfico relacionando os parâmetros do modelo como função da temperatura. A partir da observação do comportamento de cada parâmetro do modelo, foi proposto um modelo que descrevesse a variação desse parâmetro em função da temperatura. Então, foi proposto o modelo matemático generalizado, ajustado por regressão não linear, para descrever a razão de umidade como função do tempo e da temperatura.

\section{RESULTADOS E DISCUSSÃO}

A Figura 1 mostra os resultados da densidade da espuma formada em função do percentual de clara de ovo utilizada no processo. Geralmente, a densidade é utilizada para avaliar as propriedades do processo de formação de espuma. Quanto maior é a retenção de ar durante a agitação, maior é a queda do valor de densidade da espuma formada (FALADE et al., 2003).

Conforme pode ser observado na Figura 1, as espumas preparadas apresentaram densidade na faixa recomendada para a secagem em leito de espuma $(0,1$ a $0,6 \mathrm{~g} / \mathrm{mL})$, conforme Van Arsdel (1964). Observou-se um decaimento exponencial da densidade da espuma e o seguinte modelo foi ajustado, obtendo-se um coeficiente de determinação de 0,98:

$$
\rho=0,1090+0,1881 e^{-0,05 P_{c}}
$$

Em que $\rho$ é a densidade da espuma, em $\mathrm{g} / \mathrm{ml}$, e $P_{c}$ é o percentual de clara de ovo na mistura, em \%. Nota-se que a densidade diminui à medida que aumenta o percentual de clara de ovo na mistura, sendo que a partir de $52 \%$, essa redução na densidade é muito pequena.

Essa diminuição do valor da densidade das espumas ocorre devido à incorporação de ar durante a etapa de agitação, uma vez que a alta velocidade de agitação promove um aumento na taxa de cisalhamento, favorecendo a divisão das bolhas de ar, resultando na incorporação de maior quantidade de ar à mistura e, consequentemente, na diminuição da densidade da espuma. (CRUZ, 2013). Resultados semelhantes foram relatados por Abbasi e Azizpour (2016) que 
avaliaram os efeitos da adição de clara de ovo para espuma de ginja, e também por Falade et al. (2003) para a espuma de caupi e por Krasaekoopt e Bhatia (2012) para iogurte em pó produzido pelo método de secagem em leito de espuma.

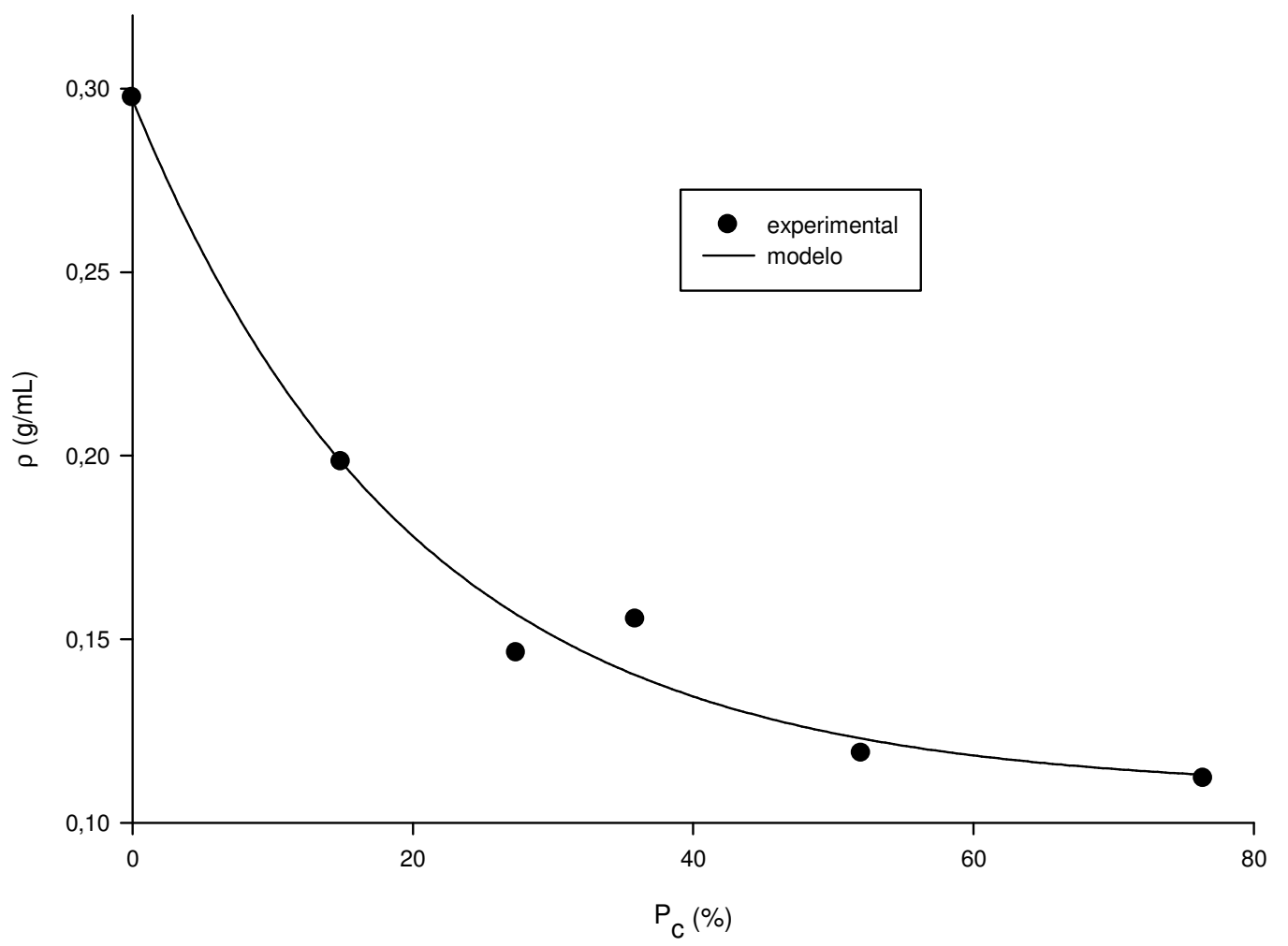

FIGURA 1 - Densidade da espuma formada versus o percentual de clara utilizada.

A Figura 2 mostra os resultados do percentual de volume drenado da espuma formada em função do percentual de clara de ovo utilizada no processo. Uma espuma de estrutura estável é necessária para uma secagem rápida, além de facilitar a remoção do material seco das bandejas de secagem. Se a espuma é facilmente coalescida, o tempo necessário para a secagem é aumentado e a qualidade do produto resultante diminui. A estabilidade da espuma é influenciada pela espessura, permeabilidade da interface ar-líquido, distribuição e tamanho das bolhas de ar e adesão (BAG et al., 2011). A drenagem provocará um afinamento da lamela e, dessa forma, aumentará a probabilidade de colapso da bolha (DURIAN; WEITZ, 1994).

Observou-se um decaimento exponencial do volume drenado e o seguinte modelo foi ajustado, obtendo-se um coeficiente de determinação de 0,99:

$$
P V D=74,3728 e^{-0,4426 P_{c}^{0.4696}}
$$

Em que $P V D$ é o percentual de volume drenado da espuma, em \%, e $P_{c}$ é o percentual de clara de ovo na mistura, em \%. Nota-se que o percentual de volume 
drenado diminui à medida que se aumenta o percentual de clara de ovo na mistura, sendo que a partir de $52 \%$, essa redução é muito pequena.

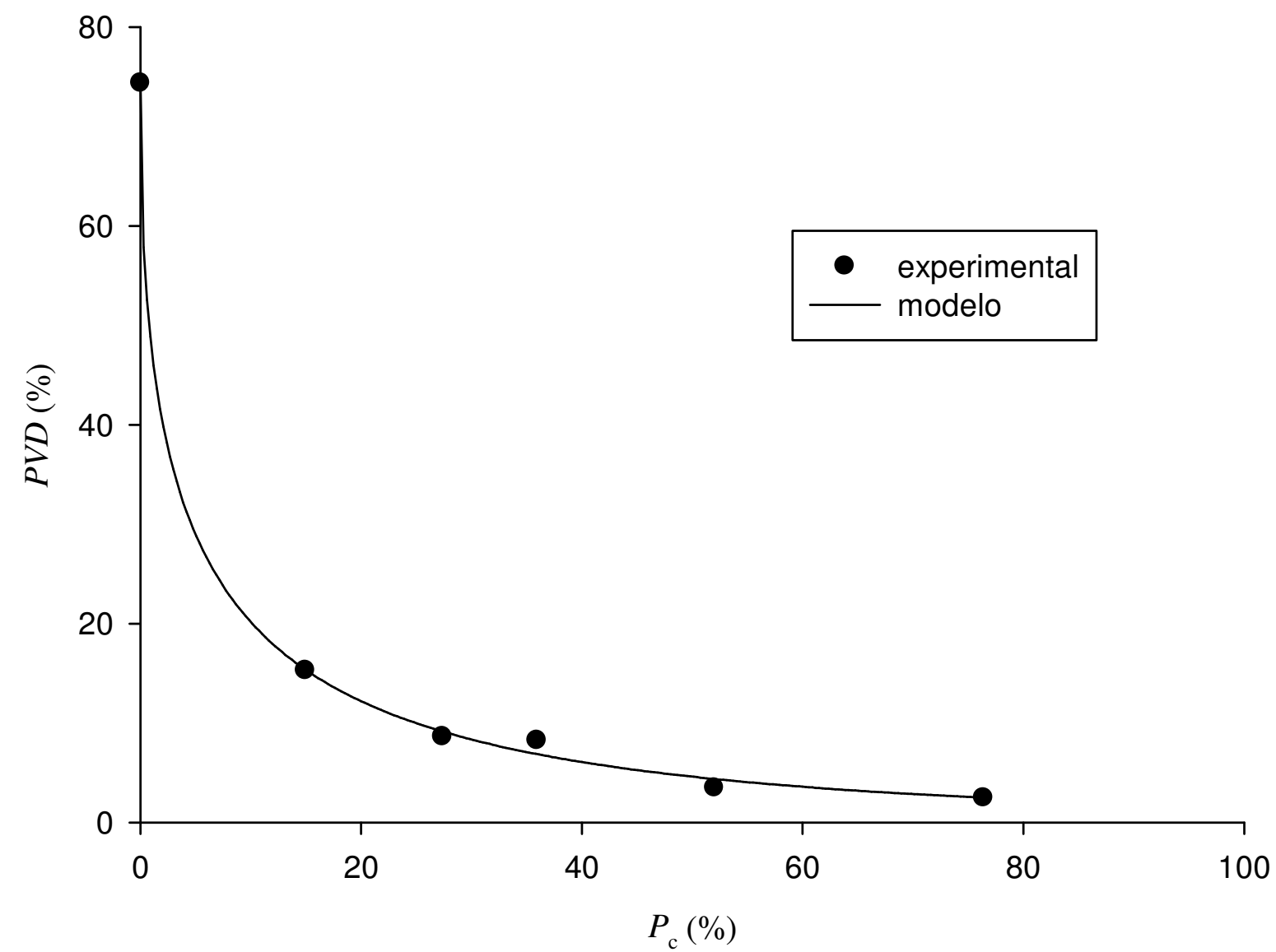

FIGURA 2 - Percentual de volume drenado 30 minutos após a interrupção da agitação versus o percentual de clara na mistura.

De maneira semelhante, Abbasi e Azizpour (2016) estudaram os efeitos da clara de ovo e de metilcelulose na secagem da polpa de ginja e observaram que o aumento da concentração dos agentes espumantes resultou em uma redução na densidade e aumento na estabilidade da espuma. $O$ aumento da porcentagem de clara de ovo adicionada reduz a tensão superficial, devido ao movimento dos agentes espumantes da fase aquosa para a interface ar-líquido. Este mecanismo leva a um aumento na capacidade de formação de espuma e a uma redução na densidade. (KARIM; WAI, 1999).

Assim, para os experimentos de secagem, optou-se por utilizar a mistura contendo $52 \%$ de clara de ovo, uma vez que um aumento no percentual de clara a partir desse nível não reduz o percentual de volume drenado e, por conseguinte, não aumentaria de forma significativa a estabilidade da espuma formada. Escolhida a melhor proporção de clara a ser adicionada ao soro de leite para obtenção de espuma estável, a secagem pode ser iniciada.

A partir dos dados experimentais de secagem, foram ajustados os modelos de Page, Henderson e Pabis (H\&P) e Lewis por meio de regressão não linear. A Tabela ENCICLOPÉDIA BIOSFERA, Centro Científico Conhecer - Goiânia, v.14 n.26; p.352 
2 apresenta os modelos ajustados e os valores de coeficientes de determinação e de erro padrão da regressão para todas as temperaturas testadas. Todos os modelos testados foram significativos pela análise de variância da regressão e pelo teste $t$ dos parâmetros, ambos a $5 \%$ de significância, em todas as temperaturas de secagem. Nota-se que o modelo de Page foi o que melhor se ajustou às curvas de secagem em todas as temperaturas testadas, uma vez que foi o modelo que obteve os maiores valores de coeficiente de determinação e os menores valores de erro padrão da regressão.

TABELA 2 - Modelos ajustados para curvas de secagem em diferentes temperaturas de secagem e valores de coeficientes de determinação e de erro padrão da regressão.

\begin{tabular}{|c|c|c|c|c|}
\hline Temperatura & Modelo & Equação ajustada & $r^{2}$ & $S$ \\
\hline \multirow{3}{*}{$50^{\circ} \mathrm{C}$} & Page & $R U=e^{-0,002106 \mathrm{t}^{1,4815}}$ & 0,9943 & 0,001357 \\
\hline & $H \& P$ & $R U=1,0671 e^{-0,01688 \mathrm{t}}$ & 0,9727 & 0,006122 \\
\hline & Lewis & $R U=e^{-0,01578 \mathrm{t}}$ & 0,9678 & 0,007166 \\
\hline \multirow{3}{*}{$55^{\circ} \mathrm{C}$} & Page & $R U=e^{-0,00151 t^{1,5778}}$ & 0,9964 & 0,000819 \\
\hline & $H \& P$ & $R U=1,0795 e^{-0,01774 t}$ & 0,9678 & 0,006969 \\
\hline & Lewis & $R U=e^{-0,01641 t}$ & 0,9605 & 0,008486 \\
\hline \multirow[t]{3}{*}{$60^{\circ} \mathrm{C}$} & Page & $R U=e^{-0,002027 t^{1.5617}}$ & 0,9967 & 0,000746 \\
\hline & $H \& P$ & $R U=1,0728 e^{-0,02048 \mathrm{t}}$ & 0,9713 & 0,006243 \\
\hline & Lewis & $R U=e^{-0,01911 t}$ & 0,9655 & 0,007468 \\
\hline \multirow[t]{3}{*}{$65^{\circ} \mathrm{C}$} & Page & $R U=e^{-0,002654 \mathrm{t}^{1,5134}}$ & 0,9953 & 0,001014 \\
\hline & $H \& P$ & $R U=1,0635 e^{-0,02145 t}$ & 0,9735 & 0,005652 \\
\hline & Lewis & $R U=e^{-0,02018 \mathrm{t}}$ & 0,9690 & 0,006568 \\
\hline \multirow[t]{3}{*}{$70^{\circ} \mathrm{C}$} & Page & $R U=e^{-0,004591 t^{1,417}}$ & 0,9956 & 0,00091 \\
\hline & $H \& P$ & $R U=1,0482 e^{-0,02403 \mathrm{t}}$ & 0,9800 & 0,004078 \\
\hline & Lewis & $R U=e^{-0,02296 t}$ & 0,9775 & 0,004584 \\
\hline
\end{tabular}

As curvas de secagem ajustadas e experimentais para as diferentes temperaturas de secagem testadas são mostradas na Figura 3. Observa-se que o modelo de Page foi o que mais se aproximou dos dados experimentais em todas as temperaturas testadas, confirmando que, dentre os três modelos utilizados, este foi o melhor ajustado. O modelo de Page também mostrou-se adequado para outros alimentos adicionados de albumina, tais como acerola (ARAÚJO et al., 2017), abacaxi (HOFSKY et al., 2009), maçã (KALETA et al., 2013) e tomate (CELMA et al., 2011). 


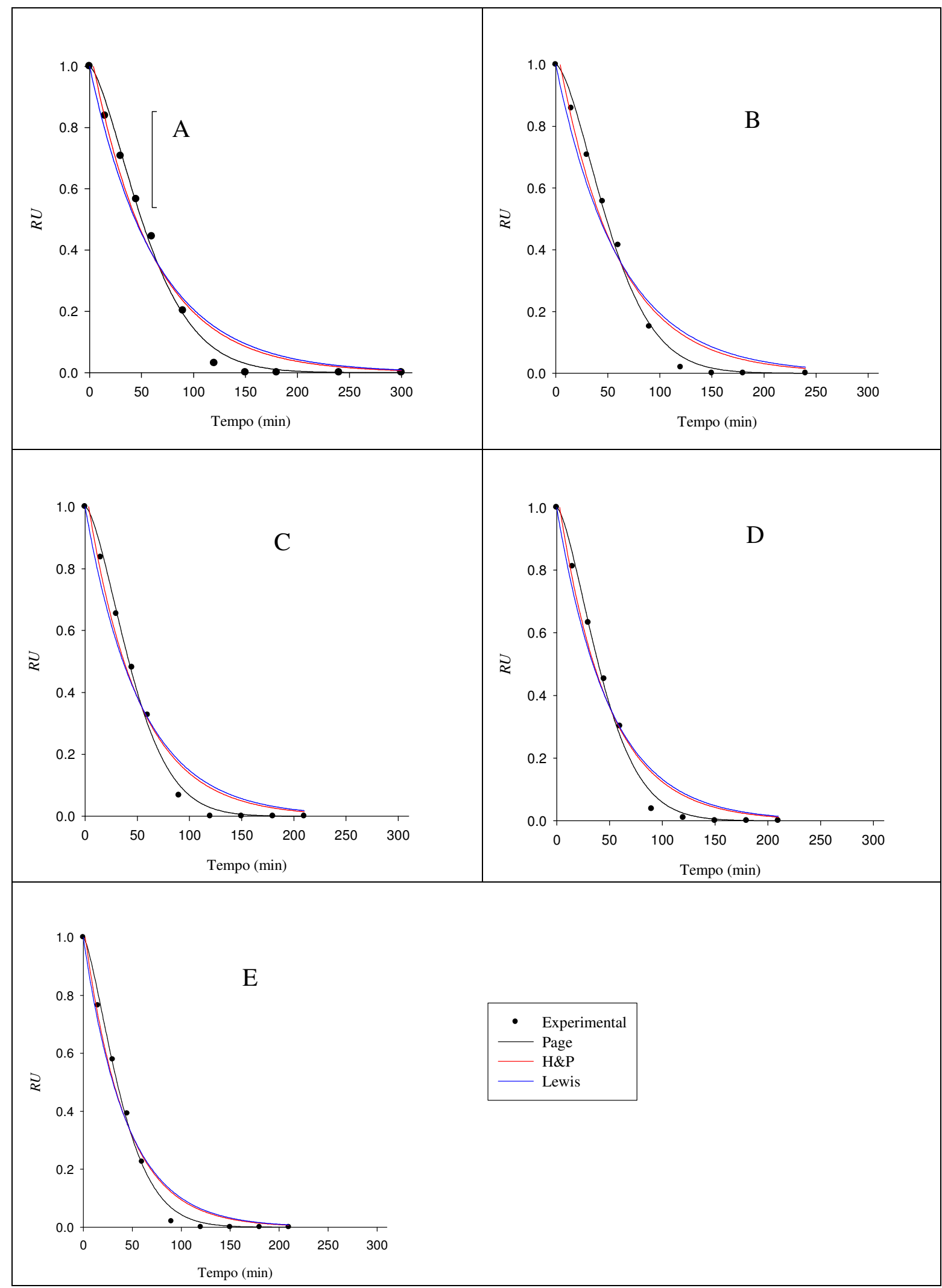

FIGURA 3 - Curvas de secagem experimentais e ajustadas pelos modelos de Page, H\&P e Lewis para as seguintes temperaturas de secagem: A: $50^{\circ} \mathrm{C}$; B: $55^{\circ} \mathrm{C}$; C: $60^{\circ} \mathrm{C}$; D: $65^{\circ} \mathrm{C}$ e $\mathrm{E}$ : $70^{\circ} \mathrm{C}$. Fonte: Os próprios autores. 
Escolhido o modelo de Page como o que melhor descreve a cinética de secagem da espuma em estudo, foi feita uma avaliação sobre como a temperatura influência nos parâmetros do modelo de Page. Inicialmente calculou-se o coeficiente de variação desses parâmetros obtidos nas diferentes temperaturas (os valores dos parâmetros são mostrados na Tabela 2 para cada temperatura testada). Para 0 parâmetro $k$ o coeficiente de variação foi de $46,41 \%$ e para o parâmetro $n$ o coeficiente de variação foi de 4,27\%. Esses resultados indicam que o parâmetro $n$ variou pouco dentro do intervalo de temperatura testado e que o parâmetro $k$ variou de forma mais pronunciada dentro desse intervalo. Assim, para a obtenção de um modelo generalizado, em que a razão de umidade seja função da temperatura e do tempo de secagem, escolheu-se um modelo com a forma do modelo de Page, no qual o parâmetro $k$ seja uma função da temperatura e o parâmetro $n$ seja independente da temperatura, ou seja,

$$
\begin{aligned}
& k=f(T) \\
& R U=e^{-[f(\tau)] t^{n}}
\end{aligned}
$$

Uma vez que o parâmetro $k$ está relacionado com a velocidade de secagem, este depende diretamente da difusividade efetiva do vapor d'água no processo de secagem. Um dos modelos mais usados para descrever a variação da difusividade efetiva em função da temperatura de secagem é o modelo de Arrhenius, dado pela seguinte equação:

$$
D_{e f}=D_{e} e^{\frac{-E_{a}}{R T}}
$$

Em que $D_{e f}$ e a difusividade efetiva, $E_{a}$ é a energia de ativação, $R$ é a constante universal dos gases ideais, $T$ é a temperatura absoluta e $D_{o}$ é o parâmetro pré-exponencial. Assim, escolheu-se como $f(T)$ uma função com o mesmo formato que a Equação de Arrhenius, conforme Eq.10.

$$
k=f(T)=k_{1} e^{\frac{-k_{z}}{T}}
$$

Substituindo a Eq.10 na Eq.8 obtém-se o modelo generalizado:

$$
R U=e^{-\left(k_{1} e^{\frac{-k_{2}}{T}}\right) t^{n}}
$$

Em que a razão de umidade, $R U$, é função da temperatura $T$, em kelvin, e do tempo $t$, em min e $k_{1}, k_{2}$ e $n$ são parâmetros do modelo. Utilizando todos os dados experimentais das curvas de secagem de todas as temperaturas testadas, os parâmetros da Eq.11 foram ajustados por meio de regressão não linear, obtendo-se o seguinte modelo:

$$
R U=e^{-\left(24,4108 e^{\frac{-30741099}{T}}\right) t^{1,5115}}
$$


Esse modelo foi significativo $(p<0,05)$ pela análise de variância da regressão e pelo teste t para os parâmetros, tendo obtido um coeficiente de determinação de 0,995 . A Figura 4 mostra o gráfico dos valores preditos pelo modelo generalizado versus os valores experimentais. Nota-se que os valores estão próximos e aleatoriamente dispersos em torno da bissetriz (função identidade), o que indica uma boa qualidade do ajuste.

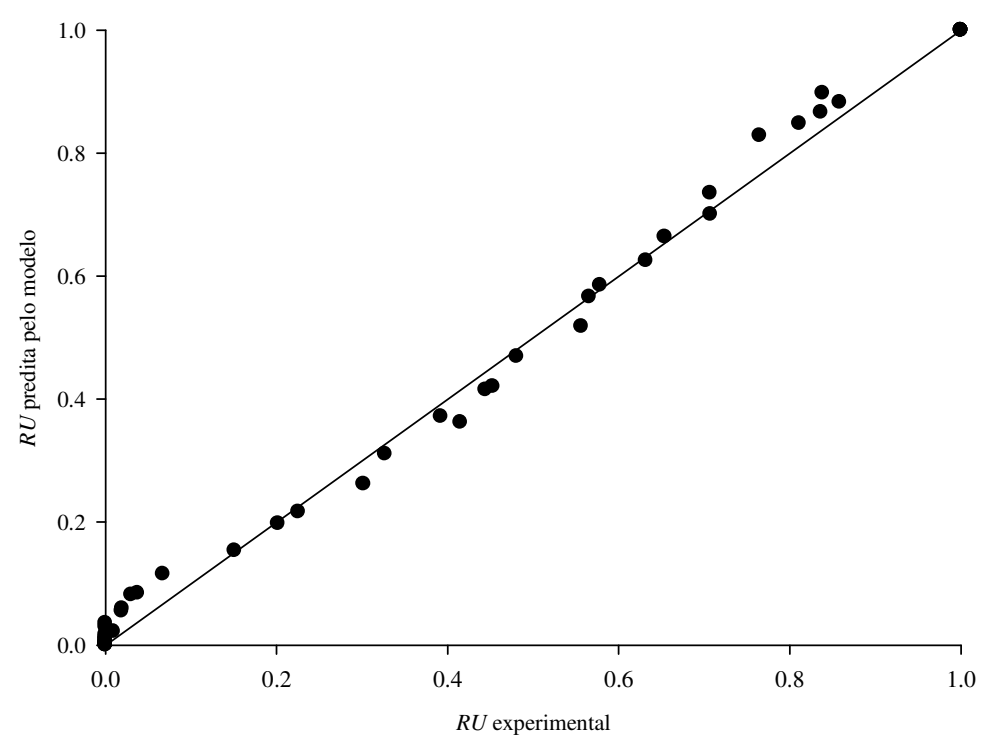

FIGURA 4 - Valores de razão de umidade preditos pelo modelo generalizado versus os valores de razão de umidade experimentais. A linha cheia representa a função identidade. Fonte: Os próprios autores.

O pó resultante da secagem apresentou característica esponjosa e de boa qualidade como mostrado na figura 5.
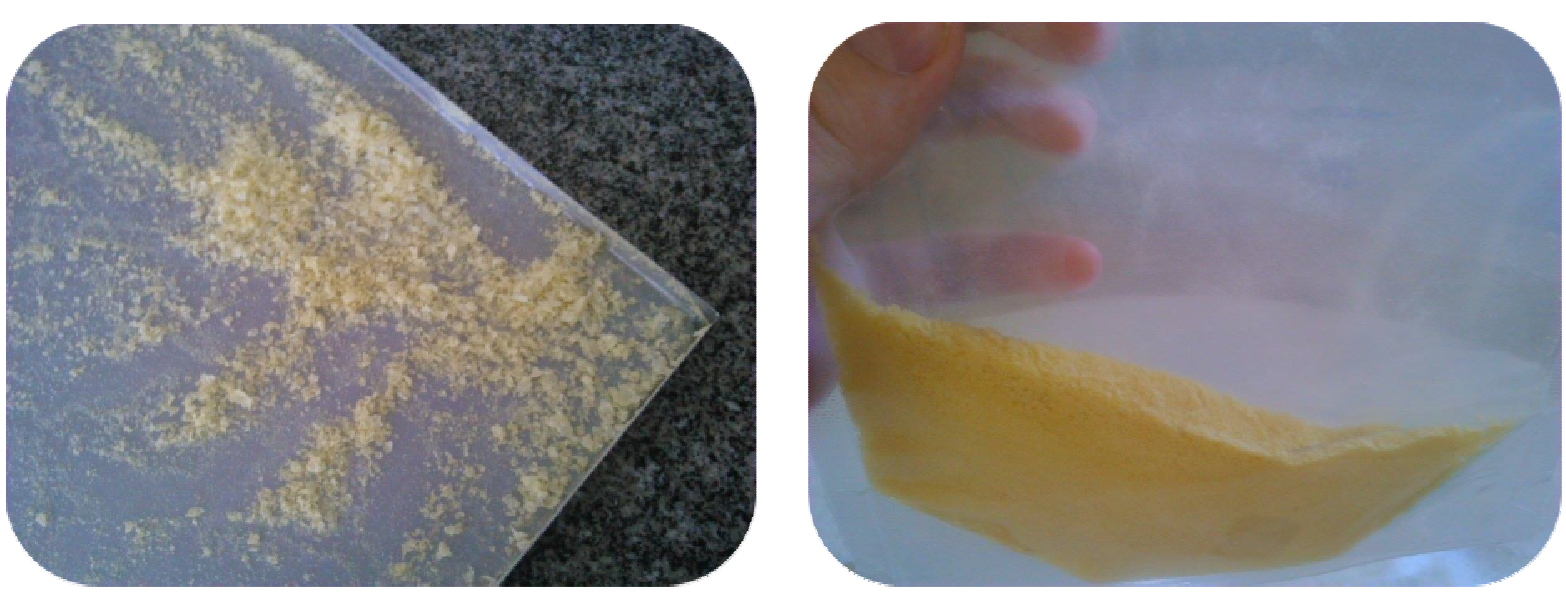

FIGURA 5 - Produto seco ainda na bandeja e produto seco após trituração 
Os valores obtidos para umidade final do pó variaram de $2 \%$ na temperatura de secagem mais alta $\left(70^{\circ} \mathrm{C}\right)$ até $8,5 \%$, na temperatura mais baixa de secagem $\left(50^{\circ} \mathrm{C}\right)$, os quais mostraram-se muito satisfatórios devido à baixa atividade de água presente e a melhor estabilidade e conservação do produto final. Resultado semelhante foi encontrado por Breda et al., (2013) para polpa de cajá-manga e por ARAÚJO et al., (2017) para acerola. O baixo teor de umidade minimiza o desenvolvimento de microrganismos e consequentemente, aumenta a estabilidade do produto (BREDA et al., 2013).

Verificou-se que a umidade do pó obtido do processo de secagem em leito em espuma caiu com o aumento da temperatura, sendo que a taxa de variação da umidade é maior, em valor absoluto, quando aumenta-se a temperatura. Um modelo matemático que possui tal comportamento é o modelo racional. Assim, ajustou-se o seguinte modelo, obtendo-se um coeficiente de determinação de 0,99:

$U=\frac{9,6235-0,1355 T}{1-0,01332 T}$

Em que $U$ é a umidade do material desidratado, em base úmida, e $T$ é a temperatura de secagem, em ${ }^{\circ} \mathrm{C}$. A Figura 6 mostra os dados experimentais de umidade e o modelo ajustado.

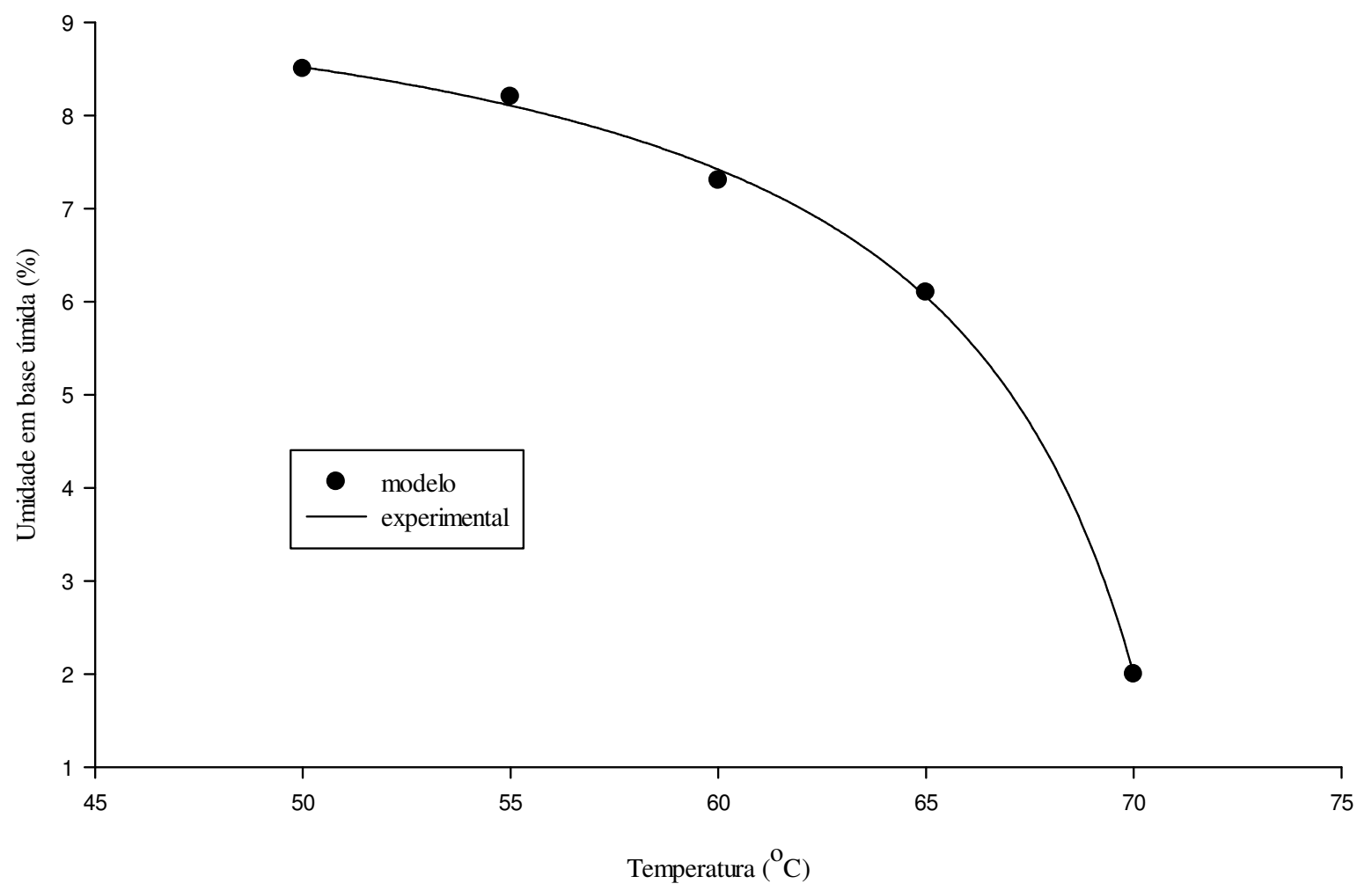

FIGURA 6 - Umidade em base úmida do material desidratado versus a temperatura de secagem. 


\section{CONCLUSÕES}

Nas condições estabelecidas e válidas para o estudo pode-se inferir que o aumento da proporção de clara de ovo adicionada ao soro de leite reduziu a densidade da espuma formada e melhorou a estabilidade.

Para os ensaios de secagem, o modelo de Page foi o que melhor se adequou aos dados experimentais, apresentando, para todas as temperaturas selecionadas, os maiores valores de coeficiente de determinação ajustado $\left(R^{2}{ }_{a d j}\right)$, acima de 0,99 , e os menores valores para o erro padrão da regressão $(S)$, sendo condizente com outros trabalhos já realizados.

O modelo generalizado ajustado apresentou alto coeficiente de determinação, indicando que este foi adequado para estimar a razão de umidade do soro de leite em função da temperatura do ar de secagem e do tempo de secagem.

O aumento da temperatura do ar reduziu o tempo de secagem do soro de leite e a umidade do produto desidratado, satisfazendo os requisitos para um produto de boa qualidade.

Dessa forma, o estudo do processo de secagem e o ajuste de modelos matemáticos podem ser aplicados para outros alimentos e contribuir para a otimização dos mesmos.

\section{AGRADECIMENTO}

Os autores agradecem a Fundação de Amparo à Pesquisa do Espírito Santo pelo financiamento deste trabalho, sem este auxílio, não seria possível a realização do mesmo.

\section{REFERÊNCIAS}

ABBASI, E., AZIZPOUR, M., Evaluation of Physicochemical Properties of Foam Mat Dried Sour Cherry Powder, LWT - Food Science and Technology, 2016. Disponível em: <http://dx.doi.org/10.1016/j.Iwt.2015.12.004>. doi: 10.1016/j.Iwt.2015.12.004

ARAUJO, C.S; MACEDO, L.L.; VIMERCATI, W.C.; SARAIVA, S.H.; OLIVEIRA, A.N.; TEIXEIRA, L.J.Q. Foam-mat drying kinetics for acerola and adjustment of the mathematical models. Brazilian Journal Food Technology., v. 20, e2016152, 2017. Disponível em: <http://dx.doi.org/10.1590/1981-6723.15216>. doi: 10.1590/19816723.15216

BAG, S.K.; SRIVASTAV, P.P.; MISHRA, H.N. Optimization of process parameters for foaming of bael (Aegle marmelos L.) fruit pulp. Food Bioprocess Technology. v.4, p. 1450-1458, 2011. Disponível em: <https://doi.org/10.1007/s11947-009-0243-6>. doi: $10.1007 / \mathrm{s} 11947-009-0243-6$

BREDA, C.A.; JUSTI, P.N.; SANJINEZ-ARGANDOÑA, E.J. Effect of foam mat dehydration in cajamanga pulp vitamin $C$ retention. Brazilian Journal Food Technology., v.24, n.2, p. 189-193, 2017. Disponível em: http://servbib.fcfar.unesp.br/seer/index.php/alimentos/article/view/189/2273. ISSN 2179-4448 (online) 
CELMA, A. R.; CUADROS, F.; LÓPEZ-RODRíGUEZ, F. Convective drying characteristics of sludge from treatment plants in tomato processing industries. Food and Bioproducts Processing, v. 90, n. 2, p. 224-234, 2011. Disponível em: <http://dx.doi.org/10.1016/j.fbp.2011.04.003>. doi: 10.1016/j.fbp.2011.04.003

CUNNINGHAM, F.E.; LINEWEAVER, H. Stabilization of egg-white proteins to pasteurizing temperatures above $60^{\circ} \mathrm{C}$. Food Technology, v.19, p.1142-1447, 1965. Disponível em: <https://archive.org/details/heatstabilityofe7439line>. ark: /13960/t2x36wr90

CRUZ, W.F. Obtenção de polpa de goiaba (Psidium guajava L.) em pó pelo método de secagem em cama da de espuma. Universidade Federal de Viçosa, 2013. 93 f. Dissertação (Mestrado em Ciência e Tecnologia em Alimentos) Universidade Federal de Viçosa, Viçosa, Minas Gerais, 2013. Disponível em: <http://alexandria.cpd.ufv.br:8000/teses/ciencia\%20e\%20tecnologia\%20de\%20alime ntos/2013/250527f.pdf. > Acesso em: 20 jan 2016.

DURIAN, D.J.; WEITZ, D.A. IN M. H. GRANT (Ed.), Encyclopedia of Chemical Technology (p. 783). New York: Wiley, 1994.

FALADE, K.O., ADEYANJU, K.I., \& UZO-PETERS, P.I. Foam-mat drying of cowpea (Vignaunguiculata) using glycerylmonostearate and egg albumin as foaming agents. Journal of European Food Research Technology, v. 217, p. 486-491, 2003. Disponível em: <https://doi.org/10.1007/s00217-003-0775-3>. doi: 10.1007/s00217003-0775-3

FELLOWS, P.J. Tecnologia do processamento de alimentos: Princípios e Práticas. $2^{\mathrm{a}}$ ed. Porto Alegre: Editora Artmed, 2006.

FRANCO, T.S.; PERUSSELLO, C.A.; ELLENDERSEN, L.S.N.; MASSON, M.L. Foam mat drying of yacon juice: Experimental analysis and computer simulation. Journal of Food Engineering. V. 158, p. 48-57. 2015. Disponível em: <https://doi.org/10.1016/j.jfoodeng.2015.02.030>.doi:10.1016/j.jfoodeng.2015.02.030

HOFSKY, A. V.; GOMES, J. P.; BARROS NETO, A. L.; SILVA, F. L. H.; ALMEIDA, F. A. C. Cinética de secagem de abacaxi cv pérola em fatias. Revista Brasileira de Produtos Agroindustriais, v. 11, n. 2, p. 123-128, 2009. Disponível em: <http://dx.doi.org/10.15871/1517-8595/rbpa.v11n2p123-128>. doi: 10.15871/15178595/rbpa.v11n2p123-128

KALETA, A.; GÓRNICKI, K.; WINICZENKO, R.; CHOJNACKA, A. Evaluation of drying models of apple (var. Ligol) dried in a fluidized bed dryer. Energy Conversion and Management, v. $67, \quad$ p. 179-185, 2013. Disponível em: $<$ http://dx.doi.org/10.1016/j.enconman.2012.11.011 >.doi:10.1016/j.enconman.2012.1 1.011 
KARIM, A. A.; WAI, C. C. Foam-mat drying starfruit (Averrhoa carambola L.) purée. Stability anda ir drying characteristics. Food Chemistry. n.64, p.337 - 343, 1999. Disponível em: <https://doi.org/10.1016/S0308-8146(98)00119-8>. doi: 10.1016/S0308-8146(98)00119-8

KRASAEKOOPT, W.; BHATIA, S. Production of Yogurt Powder Using Foam-Mat Drying. Journal of Technology, v. 15, p. 166-171, 2012. Disponível em: <http://www.journal.au.edu/au_techno/2012/jan2012/journal153_article05.pdf>

MADUREIRA, A. R.; TAVARES, T.; GOMES, A. M. P.; PINTADO, M. E.; MALCATA, F. X. Invited review: physiological properties of bio-active peptides obtained from whey protein. Journal of Dairy Science, v.93, n.2, 437-455, 2010. Disponível em: <https://doi.org/10.3168/jds.2009-2566>. doi: 10.3168/jds.2009-2566.

MELO, K.S.; FIGUEIRÊDO, R.M.F.; QUEIROZ, A.J.M.; FERNANDES, T.K.S.; BEZERRA, M.C.T. Secagem em camada de espuma da polpa do fruto do mandacaru: experimentação e ajustes de modelos matemáticos. Revista Caatinga. V. 26, n. 2, $\quad$ p. 10-17, 2013. Disponível em: < http://www.redalyc.org/html/2371/237128133002/>. ISSN: 1983-2125 (online).

MUTHUKUMARAN, A.; RATTI, C.; RAGHAVAN V.G.S. Foam-Mat Freeze Drying of Egg White and Mathematical Modeling Part I Optimization of Egg White Foam Stability. Drying Technology, 26: 508-512, 2008. Disponível em: <http://dx.doi.org/10.1080/07373930801929581 >. doi: 10.1080/07373930801929581

PERREAULT, V.; MORIN, P.; POULIOT, Y.; BRITTEN, M. Effect of denatured whey protein concentrate and its fractions on rennet-induced milk gels. International Dairy Journal. V. 64, p. 48-55. 2017. Disponível em: <https://doi.org/10.1016/j.idairyj.2016.09.005>. doi: 10.1016/j.idairyj.2016.09.005

SERAFINI, S.; SOARES, J.G.; SILVA, K.C.C.; MANENTEBOIAGO, M. Produção, Estrutura e Processamento de Ovos. SB Rural, Ed. 149, Ano 7. 2015. Disponível em: http://www.ceo.udesc.br/arquivos/id_submenu/285/caderno_udesc_149.pdf. Acesso em: 01 setembro, 2017.

VAN ARSDEL, W. B. Food dehydration. Westport, Connectucut: The Avi Publishing Company, 1964. V.2, $721 \mathrm{p}$.

VARGAS, D. P.; NÖRNBERG, J.L.; RITT, L.A.; SHEIBLER, R.B.; RIZZO, F.A.; MILAN, M.P. Potencialidades funcionais e nutracêuticas das proteínas do leite bovino. REGET, v. 18. Ed. Especial, p. 25-35, mai/2014. Disponível em: <http://dx.doi.org/10.5902/2236117012986>. doi: 10.5902/2236117012986 